\title{
Cluster Models of FeMoco with Sulfide and Carbyne Ligands: Effect of Interstitial Atom in Nitrogenase Active Site
}

Linh Le, Gwendolyn Bailey, Anna Scott, Theodor Agapie

Submitted date: 18/05/2021 P Posted date: 20/05/2021

Licence: CC BY-NC-ND 4.0

Citation information: Le, Linh; Bailey, Gwendolyn; Scott, Anna; Agapie, Theodor (2021): Cluster Models of FeMoco with Sulfide and Carbyne Ligands: Effect of Interstitial Atom in Nitrogenase Active Site. ChemRxiv. Preprint. https://doi.org/10.26434/chemrxiv.14614152.v1

Nitrogen-fixing organisms perform dinitrogen reduction to ammonia at an iron- $\mathrm{M}(\mathrm{M}=\mathrm{Mo}, \mathrm{Fe}$, or $\mathrm{V})$ cofactor (FeMco) of nitrogenase. FeMoco displays eight metal centers bridged by sulfides and a carbide having the $\mathrm{MoFe}_{7} \mathrm{~S}_{8} \mathrm{C}$ cluster composition. The role of the carbide ligand, a unique motif in protein active sites, remains poorly understood. Toward addressing its function, we isolated synthetic models of subsite $\mathrm{MFe}_{3} \mathrm{~S}_{3} \mathrm{C}$ displaying sulfides and a carbyne ligand. We developed synthetic protocols for structurally related clusters, $\left[\mathrm{Tp}^{*} \mathrm{MFe}_{3} \mathrm{~S}_{3} \mathrm{X}\right]^{\mathrm{n}-}$, where $\mathrm{M}=\mathrm{Mo}$ or $\mathrm{W}$, the bridging ligand $\mathrm{X}=\mathrm{CR}, \mathrm{N}, \mathrm{NR}, \mathrm{S}$, and $\mathrm{Tp}^{*}=$ tris(3,5-dimethyl-1-pyrazolyl)hydroborate, to study the effects of the identity of the heterometal and the bridging $\mathrm{X}$ group on structure and electrochemistry. While the nature of $\mathrm{M}$ results in minor changes, the $\mu_{3}$-bridging ligand $X$ has a large impact on reduction potentials, with differences higher than $1 \mathrm{~V}$, even for the same formal charge, the most reducing clusters being supported by the carbyne ligand.

File list (1) 


\title{
Cluster Models of FeMoco with Sulfide and Carbyne Ligands: Effect of Interstitial Atom in Nitrogenase Active Site
}

\author{
Linh N. V. Le ${ }^{1}$, Gwendolyn A. Bailey ${ }^{1}$, Anna G. Scott ${ }^{1}$, Theodor Agapie ${ }^{1 *}$ \\ ${ }^{1}$ Division of Chemistry and Chemical Engineering, California Institute of Technology, Pasadena, California \\ 91125, United States
}

*To whom correspondence may be addressed. Email: agapie@caltech.edu

\begin{abstract}
Nitrogen-fixing organisms perform dinitrogen reduction to ammonia at an iron-M ( $\mathrm{M}=\mathrm{Mo}, \mathrm{Fe}$, or $\mathrm{V})$ cofactor (FeMco) of nitrogenase. FeMoco displays eight metal centers bridged by sulfides and a carbide having the $\mathrm{MoFe}_{7} \mathrm{~S}_{8} \mathrm{C}$ cluster composition. The role of the carbide ligand, a unique motif in protein active sites, remains poorly understood. Toward addressing its function, we isolated synthetic models of subsite $\mathrm{MFe}_{3} \mathrm{~S}_{3} \mathrm{C}$ displaying sulfides and a carbyne ligand. We developed synthetic protocols for structurally related clusters, $\left[\mathrm{Tp}^{*} \mathrm{MFe}_{3} \mathrm{~S}_{3} \mathrm{X}\right]^{\mathrm{n}-}$, where $\mathrm{M}=\mathrm{Mo}$ or $\mathrm{W}$, the bridging ligand $\mathrm{X}=\mathrm{CR}, \mathrm{N}, \mathrm{NR}, \mathrm{S}$, and $\mathrm{Tp}^{*}=$ tris(3,5-dimethyl-1-pyrazolyl)hydroborate, to study the effects of the identity of the heterometal and the bridging $\mathrm{X}$ group on structure and electrochemistry. While the nature of $\mathrm{M}$ results in minor changes, the $\mu_{3}$-bridging ligand $X$ has a large impact on reduction potentials, with differences higher than $1 \mathrm{~V}$, even for the same formal charge, the most reducing clusters being supported by the carbyne ligand.
\end{abstract}

\section{Introduction}

Biological dinitrogen conversion to ammonia is performed by nitrogenases, a class of enzymes displaying several complex iron-sulfur clusters. ${ }^{1}$ The site of $\mathrm{N}_{2}$ reduction in the most efficient nitrogenase is a heterometallic cluster displaying $\mathrm{Fe}$ and $\mathrm{Mo}$, the iron-molybdenum cofactor (FeMoco). ${ }^{1}$ Two other nitrogenases are known, where $\mathrm{Fe}$ or $\mathrm{V}$ are found at the Mo position. FeMoco consists of $\mathrm{Fe}_{4} \mathrm{~S}_{3} \mathrm{C}$ and $\mathrm{MoFe}_{3} \mathrm{~S}_{3} \mathrm{C}$ cubanes with $\mu_{3}$-sulfides joined together by a shared interstitial $\mu_{6}$-carbide and 3 additional sulfides that bind in $\mu_{2}$-fashion (Figure 1). ${ }^{2}$ The impact of the carbide ligand on the electronic structure and reactivity of the cofactor, and therefore its catalytic behavior, is unclear. ${ }^{3}$ The carbide ligand is not lost during catalysis, and a direct role in bond breaking and bond making steps has been speculated. ${ }^{3}$ To address the effect of carbon-based ligands for $\mathrm{N}_{2}$ activation, synthetic models have included arene ${ }^{4}, \mathrm{~N}-$ heterocyclic carbene ${ }^{5}$, aryl ${ }^{6}$, and alkyl ${ }^{7,8}$ donors in mononuclear iron complexes.

Bi- and multimetallic model systems focused on interrogating the role of the interstitial atom and multimetallic effects have been targeted ${ }^{7,9-22}$, but complexes that display bridging carbide ${ }^{11,23-26}$ or even carbyne ${ }^{9,10,27}$ ligands are rare. Carbide-containing Fe clusters display four to six metal centers, but invariably are rich in $\mathrm{CO}$ ligands..$^{23,24,26}$ The presence of this strong field donor limits the comparison to FeMoco given the significantly different electronic structure conferred by the weak field sulfides. Moreover, the formal oxidation state of the Fe centers is significantly more reduced, between $\mathrm{Fe}^{0}$ and $\mathrm{Fe}^{\| l}$, than in the protein, between $\mathrm{Fe}^{\| l}$ and $\mathrm{Fe}^{\mathrm{III}}$. Recent promising advances have been made toward the incorporation of sulfide ligands into carbide-containing iron carbonyl clusters. ${ }^{10,11}$ In order to gain a more accurate understanding of the impact of the carbide on the properties of clusters related to FeMoco, metal complexes structurally related to the biological active site that are multimetallic, have multiple sulfide ligands, few $\mathrm{CO}$ ligands, bridging carbon-based ligands and oxidation states of $\mathrm{Fe}^{\mathrm{II}}-\mathrm{Fe} \mathrm{e}^{\mathrm{III}}$ are desirable. 
Toward developing synthetic methodologies to structures analogous to FeMoco that include a bridging carbon donor, we focus our initial efforts on the cubane subsite, $\mathrm{MoFe}_{3} \mathrm{~S}_{3} \mathrm{C}$ (top row, Figure 1). Because the nature of the $\mu_{2}$-bridging ligands in FeMoco is variable, with sulfide, selenide ${ }^{28}, \mathrm{CO}^{29}$ or $^{\mathrm{NH}^{30}}$ (for $\mathrm{FeVco}$ ) moieties at these positions as characterized by crystallography, the primary target was to match the composition of the cubane core. In this work, we present the preparation of a series of heterometallic iron-sulfur cubane-type clusters containing Mo or $W$ with biologically relevant $\mu_{3}$ bridging ligands $X(X=N$, $\mathrm{NR}, \mathrm{CR}$, and $\mathrm{S}$ ) incorporated at the $\mathrm{Fe}_{3}$ face - including the first examples bearing a bridging $\mathrm{CR}$ ligand. These variations in the bridging ligand result in a large shift in the biologically relevant $\mathrm{MFe}_{3}{ }^{11+} / \mathrm{MFe}_{3}{ }^{10+}$ redox couple of up to $2 \mathrm{~V}$, with the most reducing system occurring for the cluster bearing a bridging carbyne. These results suggest an important role of the interstitial carbide ligand in FeMoco in modulating the electronic properties of the cluster towards rendering it more reducing, with potential impact on $\mathrm{N}_{2}$ activation and conversion.

\section{Results and Discussion}

To rationally incorporate different ligands at the $\mu_{3}$-bridging position corresponding to the carbide, a $\mathrm{WFe}_{3} \mathrm{~S}_{3}$ cluster supported by a W-coordinated Tp* ligand, $\mathbf{1 - W}$, was selected as precursor bearing a $\mu_{3}-\mathrm{Cl}$ at the carbide position (Figure 2). ${ }^{31}$ Although heterometallic iron-sulfur clusters of the $\mathrm{MFe}_{3}$ types have been reported with $M=V, M o$ and $W$, they typically display a $\mu_{3}-S$ vertex opposite the heterometal that is difficult to substitute with other donor types relative to chloride. ${ }^{32,33}$ Indeed, starting from a $\mu_{3}-\mathrm{Cl}$ precursor offers a versatile route to incorporating biologically relevant light atoms at the bridging position, by ligand metathesis reactions. ${ }^{31}$ As an example, the $\mu_{3}$-Cl ligand can be substituted with $\mu_{3}-\mathrm{S}$ or $\mu_{3}-\mathrm{NSiMe}_{3}$ by oxidative metathesis with $\mathrm{S}_{8}$ or $\mathrm{Me}_{3} \mathrm{SiN}_{3}$, respectively. ${ }^{31}$

For the installation of a carbon-based ligand at the $\mu_{3}$ position, we were inspired by the utilization of the strained carbene bis(diisopropylamino)cyclopropenylidene (BAC) ${ }^{34}$ for promoting C-atom transfer to the $\mathrm{Fe} \equiv \mathrm{N}$ bond of the iron(IV) nitride $\left.\left[\left\{\mathrm{PhB}^{\mathrm{i}}{ }^{\mathrm{Pr}} \mathrm{I}_{2} \mathrm{Im}\right)_{3}\right\} \mathrm{Fe}(\mathrm{N})\right]\left({ }^{\mathrm{P}} \mathrm{Pr}_{2} \mathrm{Im}=1,2\right.$-diisopropylimidazolylidene) ${ }^{35}$ This ultimately generated a cyanide ligand, with the release of alkyne ${ }^{i} \mathrm{Pr}_{2} \mathrm{NC} \equiv \mathrm{CN}^{i} \mathrm{Pr}_{2}$ as the side product. Mixing 1-W with 3 equiv. of BAC in THF in the presence of $\mathrm{NaBPh}_{4}$ as a chloride abstracting agent results in the gradual disappearance of the insoluble 1-W to form a dark red solution, along with the precipitation of a colorless solid, assigned as $\mathrm{NaCl}$ (Figure 2). Upon filtration, the vapor diffusion of pentane into the filtrate over one day leads to the formation of dark purple needles. A single crystal X-ray diffraction (XRD) study of these crystals confirmed the structure of the product, where the three terminal chlorides have been substituted with BAC to give a monocationic cluster, 2-W, with a $\mathrm{BPh}_{4}$ counteranion (Figure 2). Although $\mathrm{MFe}_{3} \mathrm{~S}_{3}$ clusters supported by carbene ligands have not been structurally characterized, the $\mathrm{Fe}-$ $\mathrm{C}$ distances are in the range of $\mathrm{Fe}_{4} \mathrm{~S}_{4}$ clusters supported by $\mathrm{NHC}$ ligands. ${ }^{15,36}$

In order to promote the delivery of a $\mathrm{C}$ atom or $\mathrm{CR}$ group, at least one $\mathrm{C}-\mathrm{C}$ bond has to be cleaved, which can be achieved by metal sites by methods such as heating ${ }^{37}$, photolysis ${ }^{37}$ or reduction. ${ }^{35,38}$ While $\mathbf{2}-\mathbf{W}$ remains unchanged when irradiated with a $75 \mathrm{~W}$ Xe lamp and decomposes when heated at reflux in THF under an inert atmosphere, reduction with one equivalent of a strong reducing agent like potassium naphthalenide leads to the new cluster 3 . Instead of generating a neutral, one-electron reduced form of 2$\mathbf{W}$ and $\mathrm{KBPh}_{4}$ as byproduct, product 3 loses the $\mu_{3}-\mathrm{Cl}$ ligand as $\mathrm{KCl}$ likely driven by precipitation (Figure 2), leaving an open triangular $\mathrm{Fe}_{3}$ face, as demonstrated by XRD characterization (Figure 2).

Cluster 3 possesses a rare incomplete cubane geometry for iron-sulfur clusters. The related $\left[\mathrm{Fe}_{4} \mathrm{~S}_{3}\right]$ geometry has only been reported in the anion $\left[\mathrm{Fe}_{4} \mathrm{~S}_{3}(\mathrm{NO})_{7}\right]^{-}$of Roussin's black salt ${ }^{39}$ in inorganic compounds, and an oxygen-tolerant [NiFe]-hydrogenase in biology..$^{40}$ Incomplete heterometallic cubanes of the form $\mathrm{MFe}_{3} \mathrm{~S}_{3}$ have only been observed for $\mathrm{M}=\mathrm{Mo}$ in a synthetic system, where the Fe atoms are ligated by multiple $\mathrm{CO}$ ligands. ${ }^{41}$ The open-face $\mathrm{Fe}_{3}$ triangle resembles the sulfide-free triiron systems supported by multinucleating trisamide ligands, which can bind $\mu_{3}$-nitride or $\mu_{3}$-imide ligands. ${ }^{14,42}$ Thus, the open nature of the $\mathrm{Fe}_{3}$ cluster face in $\mathbf{3}$ make it a promising platform for the rational installation of various bridging ligands in a $\mu_{3}$ mode. 
Cluster 3 can further be reduced with an excess of $\mathrm{KC}_{8}$ to form the neutral, $\mathrm{Et}_{2} \mathrm{O}$ soluble cluster 4-W. Gratifyingly, under these highly reducing conditions, the $\mathrm{C}-\mathrm{C}$ bond in the BAC ligand is cleaved and the cyclopropene ring opens, delivering a carbyne ligand to the bridging position. The cluster loses its $\mathrm{C}_{3}$ symmetry, resulting in two Fe atoms ligated by BAC and a unique Fe center, to which the rest of the ringopened BAC ligand anchors as a vinyl fragment. To our knowledge, this is the first example of a synthetic iron-sulfur cluster without $\mathrm{CO}$ ligands that displays a carbyne donor. Aside for the bridging carbyne ligand, the terminal hydrocarbyl ligand is also notable, given the role of such ligands in SAM enzymes ${ }^{43}$ and their scarcity in iron-sulfur cluster synthetic chemistry. ${ }^{44}$ Conveniently, 4-W can also be synthesized directly from 2-W using an excess of $\mathrm{KC}_{8}$ or potassium naphthalenide without isolating 3 . This reaction stops at 3 if conducted at $-78{ }^{\circ} \mathrm{C}$ for $1 \mathrm{~h}$, while appreciable conversion to $4-\mathrm{W}$ can only be achieved at room temperature, suggesting that the ring opening and rearrangement of the BAC ligand is rate-limiting. The vinyl ligand in 4-W can be alkylated with MeOTf, leading to a five-membered amine-carbyne chelate with $\mathrm{NiPr}_{2}$ bound to the unique Fe (Figure 2). This cluster is reminiscent of a putative $\mathrm{NH}_{3}$-bound form of FeMo-Co, as it displays a bridging C-based ligand and a nitrogen donor at one of the Fe centers.

Toward preparing structural analogs of the $\mu_{3}$-carbyne ligand, 3 was investigated as a precursor to a cluster bearing $\mathrm{N}$ or $\mathrm{S}$ at the bridging position. Treatment of 3 with $\mathrm{NBu}_{4} \mathrm{~N}_{3}, \mathrm{Me}_{3} \mathrm{SiN}_{3}$ and $\mathrm{PPh}_{3} \mathrm{~S}$ (or $\mathrm{S}_{8}$ ) leads to the formation of the corresponding nitride- (6), imide- (7), and sulfide- (8) bridged clusters (Figure 3). Complexes 6, 7, and 8 are isostructural, with a WFe $\mathrm{S}_{3} \mathrm{X}(\mathrm{X}=\mathrm{N}$ or $\mathrm{S})$ cubane supported by $\mathrm{Tp}^{*}$ at W and one BAC ligand bound to each iron center (Figure 4). The presence of three BAC ligands is a distinct feature relative to 3-W and 4-W. Targeting a carbyne analog with the same number of BAC donors, compound $\mathbf{5}$ was treated with BAC; however, no reaction was observed, likely due to a combination of steric constraints and stability of the chelate.

For closer similarity to FeMoco, a Mo variant of the above clusters was targeted. The Mo-containing precursor 1-Mo was conveniently synthesized from $\left[\mathrm{NEt}_{4}\right]\left[\mathrm{Tp}^{*} \mathbf{M o S}_{5}\right]$ via $\left[\mathrm{NEt}_{4}\right]\left[\mathrm{Tp}^{*} \mathbf{M o S}_{3}\right]^{45}$ generated by sulfur abstraction with $2 \mathrm{PPh}_{3}$ (see Supporting Information). Adapting the synthetic protocol developed for 2-W, chloride substitution with BAC from 1-Mo allowed the isolation of 2-Mo. Ring opening upon reduction with $\mathrm{KC}_{8}$ resulted in the formation of 4-Mo (Figure 2). Notably, the $\mathrm{MoS}_{3} \mathrm{Fe}_{3} \mathrm{C}$ cluster core of 4Mo reproduces one half of the structure of FeMoco, including the bridging carbon donor. Further, the geometry of the unique Fe in the C-bridged clusters 4-W, 4-Mo, and 5 reproduces the four-coordinate, distorted trigonal pyramidal geometry found in the belt sites of FeMoco (Figure 2). The S-Fe-S-C and SFe-S-N torsion angles in 4-W $\left(173.2(3)^{\circ}\right)$ and $\mathbf{5}\left(154.2(3)^{\circ}\right)$ approach $180^{\circ}$, bringing these four atoms close to coplanar, which corresponds to a distorted trigonal pyramidal geometry at $\mathrm{Fe}$, leaving the axial site open for potential substrate coordination, as has been previously invoked for $\mathrm{N}_{2}$ binding in FeMoco. ${ }^{16}$ In addition, the Fe-N distance in $\mathbf{5}$ is $2.16 \AA$, close to the $\mathrm{Fe}-\mathrm{N}$ bond length in the previously characterized $\mathrm{NH}$-bound FeVco $(2.01 \pm 0.04 \AA) .{ }^{30}$ Further studies are being conducted to investigate reactivity at this site.

A comparison of the structural aspects of the reported clusters and the corresponding subsite of FeMoco is informative (Table S3). The W/Mo-S distances vary modestly $(2.34-2.39 \AA)$ in the series of cubane complexes, suggesting that that the metal oxidation state remains unchanged. Although the total redox state of the metal core varies from $\left(\mathrm{MFe}_{3}\right)^{9+}$ to $\left(\mathrm{MFe}_{3}\right)^{11+}$, it is likely that the formal oxidation state remains $\mathrm{M}^{\mathrm{III}}$, based on literature assignments for $\mathrm{MoFe}_{3} \mathrm{~S}_{4}{ }^{46}$ and $\mathrm{WFe}_{3} \mathrm{~S}_{4}{ }^{47}$ in two redox states $\left(\left(\mathrm{MFe}_{3}\right)^{10+}\right.$ and $\left.\left(\mathrm{MFe}_{3}\right)^{11+}\right)$. Additional experiments will be necessary to determine the redox state distribution between metals; nevertheless, these compounds are in the range assigned for FeMoco. ${ }^{2}$ While the average Fe-S distance tends to increase with decreasing oxidation states of the cluster ${ }^{48}$, the variation in the Fe-S bond length in this series is modest, being less than $0.04 \AA$ for individual Fe-S distances. No particular trend emerges from this comparison, likely because of the differences in the identity of the $\mu_{3}$ ligand $X$, which may play a role in modulating the Fe-S covalency. In contrast, the average Fe-Fe distance varies more significantly, from 2.41 to $2.64 \AA$, with the shortest for the carbyne complex 4-W suggesting a possible structural role of the bridging atom in tuning the level of Fe-Fe interaction. The structural parameters for the $\mathrm{W}$ and Mo analogs 4-W and 4-Mo are very similar, with the exception of the Fe-Fe distance, which increases by $\sim 0.1 \AA$ in the Mo variant, closer to the Fe-Fe distances in FeMoco of about $2.62 \AA .{ }^{49}$ This 
notable structural effect may reflect a different type of electronic interaction within the cluster as a function of the nature of metal $\mathrm{M}$. The Fe-C distances in 4-W, 4-Mo and $\mathbf{5}$ are in the range of $1.94-1.95 \AA$, which are close to the average Fe-C bond length in FeMoco of $2.00 \AA,{ }^{49}$ though shorter, likely due to bridging of the carbide between more metal centers in the biological system.

In order to probe the impact of the different bridging ligands at the position of the interstitial carbide and metals $\mathrm{M}$ on the redox potentials of the cubane models of FeMoco, we carried out a comparative cyclic voltammetry (CV) study of compounds 4 - 8 (Figure 5). Each cluster displays at least one oxidation and one reduction event, both reversible. For $\mathbf{6 , 7}$, and $\mathbf{8}$, the two $\mathrm{CV}$ features are assigned to the $\left(\mathrm{MFe}_{3}\right)^{11+} /\left(\mathrm{MFe}_{3}\right)^{10+}$ and $\left(\mathrm{MFe}_{3}\right)^{10+} /\left(\mathrm{MFe}_{3}\right)^{9+}$ couples. For 4-W, 4-Mo, and 5, they correspond to $\left(\mathrm{MFe}_{3}\right)^{12+} /\left(\mathrm{MFe}_{3}\right)^{11+}$ and $\left(\mathrm{MFe}_{3}\right)^{11+} /\left(\mathrm{MFe}_{3}\right)^{10+}$. Compounds 4-W and 4-Mo show an additional reversible event at more positive potentials, assigned to $\left(\mathrm{MFe}_{3}\right)^{13+} /\left(\mathrm{MFe}_{3}\right)^{12+}$, which might be an indication of the carbyne ligand's ability to accommodate expanded redox capabilities. Compounds $\mathbf{4}-\mathbf{8}$ can be compared using the $\left(\mathrm{MFe}_{3}\right)^{11+} /\left(\mathrm{MFe}_{3}\right)^{10+}$ couple (highlighted by boxes in Figure 5$)$, which they all display.

This comparison addresses the impact of the identity of the bridging ligand for the same redox event in isostructural clusters, while accounting to some extent for different cluster charge as the charge of the

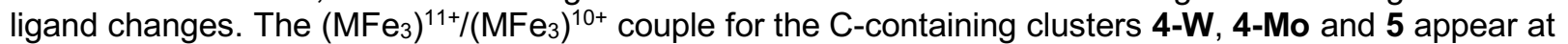
redox potentials below $-2.0 \mathrm{~V}$, significantly more negative than $6-8$ at $-0.87 \mathrm{~V}$ to $-1.16 \mathrm{~V}$. While $6-8$ contain three BAC ligands and 4-W/5 only have two, complicating comparison, compound $\mathbf{5}$ displays a weaker donor in the tertiary amine compared to BAC in 6-8 Thus, the carbyne ligand has a large impact on the redox chemistry, even beyond the $\sim 1 \mathrm{~V}$ difference observed for these compounds. Compounds 5 and 6 maintain the same formal charge for the bridging ligand (3-) as carbyne vs nitride. Still, a difference in the $\left(\mathrm{MFe}_{3}\right)^{11+} /\left(\mathrm{MFe}_{3}\right)^{10+}$ redox potentials of $1.12 \mathrm{~V}$ is observed, a remarkable impact of the $\mathrm{C}$ - vs $\mathrm{N}$ based ligands. Changing the donor from nitride (6) to imide (7) or sulfide (8) shifts the redox potential less than $200 \mathrm{mV}$ highlighting the similar impact of $\mathrm{S}$ and $\mathrm{N}$ donors on the redox chemistry, in large contrast to the carbyne.

The redox couple shifts positively by about $0.75 \mathrm{~V}$ between $\mathbf{4 - W}$ and 5 , likely because of the positive charge of $\mathbf{5}$ and the weaker electron-donating capability of the NiPr 2 group compared to the vinyl fragment. Of note, there is little impact of the identity of the Group 6 metal ( $M=$ Mo vs. W) on the reduction potentials, with a slight increase in redox potential of $70 \mathrm{mV}$ on changing $\mathrm{W}$ into Mo, though the more biologically relevant $\mathrm{Fe}$ or $\mathrm{V}$ variants remain to be pursued. In biomimetic group transfer chemistry with Mo and W, a similar modest increase in potentials of about $120 \mathrm{mV}$ is also observed for a nicotinic acid hydroxylase model when Mo is replaced with $\mathrm{W} .{ }^{50}$

These electrochemical results suggest that the interstitial carbon ligand in FeMoco may play an important role in increasing the reductive power of the clusters. While the specific oxidation states of the metal centers cannot be verified without additional spectroscopic studies, the reduced form, $\left(\mathrm{MFe}_{3}\right)^{10+}$ in $\mathbf{4 - W}$, 4Mo, and 5, corresponds to an average metal oxidation state of 2.5 , close to the one of the resting state of FeMoco, as $\mathrm{Fe}_{3}{ }_{3} \mathrm{Fe}^{\mathrm{III}}{ }_{4} \mathrm{Mo}^{\mathrm{III}}$ (average metal oxidation state 2.6 ). ${ }^{2}$ Additional reduction steps lower the average formal oxidation state of FeMoco, but not below 2 and do not bring it in the range typically observed for mononuclear Fe complexes studied for $\mathrm{N}_{2}$ activation. ${ }^{51}$ Therefore, the ability of the biological cofactor to perform $\mathrm{N}_{2}$ activation at high oxidation states is unusual. A possible explanation is charge redistribution within the cluster to increase reducing equivalents at the site of substrate binding or electronic communication between different metal sites. ${ }^{20-22,52}$ We find here that the carbyne bridging ligand has a remarkable impact on the cluster reduction potentials, with very reducing potentials for relatively high, biologically relevant metal oxidation states. Moreover, the carbyne clusters are significantly more reducing for the same redox state compared to $\mathrm{N}$ and $\mathrm{S}$ analogs.

Toward addressing the effect of the interstitial ligands of FeMoco, we have reported studies of tetranuclear Fe clusters with $\mu_{4}$-fluoride and oxide ligands. ${ }^{20}$ In those cases, the oxide makes the cluster about $1 \mathrm{~V}$ more reducing compared to fluoride for the same redox state, while also promoting NO activation. In those systems, the charge of the interstitial atom could play a role in changing the potential. Here, this series of clusters accounts for changes in ligand charge. Carbyne (5) and nitride (6) have the 
same charge, but result in $\sim 1 \mathrm{~V}$ difference in reducing power. In contrast, nitride (6) vs imide (7) and sulfide (8) have reduction potentials within $300 \mathrm{mV}$, indicating the formal charge of the ligand does not have as large impact. The ability of the carbyne to increase the reduction power is likely a consequence of its stronger interaction with the metal centers, an aspect that will be pursued in a separate study.

In the context of $\mathrm{N}_{2}$ reduction, the redox tuning observed here suggests that the interstitial carbon may allow FeMoco to access higher reducing power, enabling more facile transfer of electrons to the $\mathrm{N}_{2}$ substrate for conversion to $\mathrm{NH}_{3}$. This parallels the results from experiments using synthetic iron catalysts for $\mathrm{N}_{2}$ reduction, many of which require strong external reducing agents like $\mathrm{KC}_{8}{ }^{8,53}$ Considering the potential impact of replacing the bridging carbyne with a more biologically inexpensive sulfide, a much less reducing cluster $(\mathbf{8})$ is generated for the same redox state, $\left(\mathrm{MFe}_{3}\right)^{10+}$, and even an additional reducing equivalent in $\left(\mathrm{MFe}_{3}\right)^{9+}$ does not match with the $\left(\mathrm{MFe}_{3}\right)^{10+}$ carbyne system. Therefore, an interstitial sulfide may not provide sufficient reducing power to efficiently convert $\mathrm{N}_{2}$ into $\mathrm{NH}_{3}$, leading instead to the preference for the unusual bridging carbide motif.

In summary, we have described the synthesis of a series of heterometallic iron-sulfur clusters of the form $\mathrm{MFe}_{3} \mathrm{~S}_{3} \mathrm{X}(\mathrm{M}=\mathrm{Mo}$ or $\mathrm{W}$ and $\mathrm{X}=\mathrm{CR}, \mathrm{N}, \mathrm{NR}$ and $\mathrm{S})$ with the cubane geometry matching the structure of the $\mathrm{MFe}_{3} \mathrm{~S}_{3} \mathrm{C}$ subsite of FeMco. These include the first examples of iron-sulfur clusters containing a carbon-based ligand bridging the $\mathrm{Fe}_{3}$ face. Structural comparison by X-ray crystallography suggests that while the bond metrics are similar with $\mathrm{M}=\mathrm{Mo}$ or $\mathrm{W}$, the identity of bridging ligand $\mathrm{X}$ influences the cluster geometry considerably, with the shortest Fe-Fe distance occurring for $X=C R$. Importantly, electrochemical studies indicate that the presence of a bridging $\mathrm{C}$-atom allows the clusters to reach highly reducing states, with potential implications for $\mathrm{N}_{2}$ reduction chemistry. These studies shed new light on possible structural and electrochemical roles of the interstitial carbide ligand in nitrogenase.

\section{Materials and Methods}

See Supporting Information for experimental details.

\section{Acknowledgment}

We are grateful to the National Institutes of Health (R01-GM102687B to T.A.), Natural Sciences and Engineering Research Council of Canada (G.A.B.), the Resnick Sustainability Institute at Caltech (G.A.B.), and the National Science Foundation (Graduate Research Fellowships Program to A.G.S.) for funding. We thank the Beckman Institute and the Dow Next Generation Grant for instrumentation support. Michael Takase, Lawrence Henling, and Manar Shoshani are thanked for assistance with crystallography.

\section{References}

(1) Burgess, B. K.; Lowe, D. J. Mechanism of Molybdenum Nitrogenase. Chem. Rev. 1996, 96 (7), 2983-3012. https://doi.org/10.1021/cr950055x.

(2) Spatzal, T.; Schlesier, J.; Burger, E.-M.; Sippel, D.; Zhang, L.; Andrade, S. L. A.; Rees, D. C.; Einsle, O. Nitrogenase FeMoco Investigated by Spatially Resolved Anomalous Dispersion Refinement. Nature Communications 2016, 7 (1), 10902. https://doi.org/10.1038/ncomms10902.

(3) Siegbahn, P. E. M. Model Calculations Suggest That the Central Carbon in the FeMo-Cofactor of Nitrogenase Becomes Protonated in the Process of Nitrogen Fixation. J. Am. Chem. Soc. 2016, 138 (33), 10485-10495. https://doi.org/10.1021/jacs.6b03846.

(4) Čorić, I.; Mercado, B. Q.; Bill, E.; Vinyard, D. J.; Holland, P. L. Binding of Dinitrogen to an IronSulfur-Carbon Site. Nature 2015, 526 (7571), 96-99. https://doi.org/10.1038/nature15246. 
(5) Ung, G.; Peters, J. C. Low-Temperature $\mathrm{N}_{2}$ Binding to Two-Coordinate $\mathrm{L}_{2} \mathrm{Fe}^{0}$ Enables Reductive Trapping of $\mathrm{L}_{2} \mathrm{FeN}_{2}{ }^{-}$and $\mathrm{NH}_{3}$ Generation. Angew. Chem. Int. Ed. 2015, 54 (2), 532-535. https://doi.org/10.1002/anie.201409454.

(6) McWilliams, S. F.; Broere, D. L. J.; Halliday, C. J. V.; Bhutto, S. M.; Mercado, B. Q.; Holland, P. L. Coupling Dinitrogen and Hydrocarbons through Aryl Migration. Nature 2020, 584 (7820), 221-226. https://doi.org/10.1038/s41586-020-2565-5.

(7) Nagelski, A. L.; Fataftah, M. S.; Bollmeyer, M. M.; McWilliams, S. F.; MacMillan, S. N.; Mercado, B. Q.; Lancaster, K. M.; Holland, P. L. The Influences of Carbon Donor Ligands on Biomimetic Multi-Iron Complexes for $\mathrm{N}_{2}$ Reduction. Chem. Sci. 2020. https://doi.org/10.1039/D0SC03447A.

(8) Creutz, S. E.; Peters, J. C. Catalytic Reduction of $\mathrm{N}_{2}$ to $\mathrm{NH}_{3}$ by an $\mathrm{Fe}-\mathrm{N}_{2}$ Complex Featuring a CAtom Anchor. J. Am. Chem. Soc. 2014, 136 (3), 1105-1115. https://doi.org/10.1021/ja4114962.

(9) Arnett, C. H.; Agapie, T. Activation of an Open Shell, Carbyne-Bridged Diiron Complex Toward Binding of Dinitrogen. J. Am. Chem. Soc. 2020, 142 (22), 10059-10068.

https://doi.org/10.1021/jacs.0c01896.

(10) Joseph, C.; Cobb, C. R.; Rose, M. J. Single-Step Sulfur Insertions into Iron Carbide Carbonyl Clusters: Unlocking the Synthetic Door to FeMoco Analogues. Angew. Chem. Int. Ed. 2021, 60 (7), 34333437. https://doi.org/10.1002/anie.202011517.

(11) Liu, L.; Rauchfuss, T. B.; Woods, T. J. Iron Carbide-Sulfide Carbonyl Clusters. Inorg. Chem. 2019, 58 (13), 8271-8274. https://doi.org/10.1021/acs.inorgchem.9b01231.

(12) Ohta, S.; Ohki, Y.; Hashimoto, T.; Cramer, R. E.; Tatsumi, K. A Nitrogenase Cluster Model $\left[\mathrm{Fe}_{8} \mathrm{~S}_{6} \mathrm{O}\right]$ with an Oxygen Unsymmetrically Bridging Two Proto- $\mathrm{Fe}_{4} \mathrm{~S}_{3}$ Cubes: Relevancy to the Substrate Binding Mode of the FeMo Cofactor. Inorg. Chem. 2012, 51 (21), 11217-11219. https://doi.org/10.1021/ic301348f.

(13) Ohki, Y.; Ikagawa, Y.; Tatsumi, K. Synthesis of New [8Fe-7S] Clusters: A Topological Link between the Core Structures of P-Cluster, FeMo-Co, and FeFe-Co of Nitrogenases. J. Am. Chem. Soc. 2007, 129 (34), 10457-10465. https://doi.org/10.1021/ja072256b.

(14) Powers, T. M.; Betley, T. A. Testing the Polynuclear Hypothesis: Multielectron Reduction of Small Molecules by Triiron Reaction Sites. J. Am. Chem. Soc. 2013, 135 (33), 12289-12296. https://doi.org/10.1021/ja405057n.

(15) Brown, A. C.; Suess, D. L. M. Controlling Substrate Binding to $\mathrm{Fe}_{4} \mathrm{~S}_{4}$ Clusters through Remote Steric Effects. Inorg. Chem. 2019, 58 (8), 5273-5280. https://doi.org/10.1021/acs.inorgchem.9b00360.

(16) DeRosha, D. E.; Chilkuri, V. G.; Van Stappen, C.; Bill, E.; Mercado, B. Q.; DeBeer, S.; Neese, F.; Holland, P. L. Planar Three-Coordinate Iron Sulfide in a Synthetic [4Fe-3S] Cluster with Biomimetic Reactivity. Nature Chemistry 2019, 11 (11), 1019-1025. https://doi.org/10.1038/s41557-019-0341-7.

(17) Lee, S. C.; Holm, R. H. The Clusters of Nitrogenase: Synthetic Methodology in the Construction of Weak-Field Clusters. Chem. Rev. 2004, 104 (2), 1135-1158. https://doi.org/10.1021/cr0206216.

(18) Lee, Y.; Sloane, F. T.; Blondin, G.; Abboud, K. A.; García-Serres, R.; Murray, L. J. Dinitrogen Activation Upon Reduction of a Triiron(II) Complex. Angew. Chem. Int. Ed. 2015, 54 (5), 1499-1503. https://doi.org/10.1002/anie.201409676.

(19) Reiners, M.; Baabe, D.; Münster, K.; Zaretzke, M.-K.; Freytag, M.; Jones, P. G.; Coppel, Y.; Bontemps, S.; Rosal, I. del; Maron, L.; Walter, M. D. $\mathrm{NH}_{3}$ Formation from $\mathrm{N}_{2}$ and $\mathrm{H}_{2}$ Mediated by Molecular Tri-Iron Complexes. Nature Chemistry 2020, 12 (8), 740-746. https://doi.org/10.1038/s41557020-0483-7. 
(20) Reed, C. J.; Agapie, T. Tetranuclear Fe Clusters with a Varied Interstitial Ligand: Effects on the Structure, Redox Properties, and Nitric Oxide Activation. Inorg. Chem. 2017, 56 (21), 13360-13367. https://doi.org/10.1021/acs.inorgchem.7b02114.

(21) Arnett, C. H.; Chalkley, M. J.; Agapie, T. A Thermodynamic Model for Redox-Dependent Binding of Carbon Monoxide at Site-Differentiated, High Spin Iron Clusters. J. Am. Chem. Soc. 2018, 140 (16), 5569-5578. https://doi.org/10.1021/jacs.8b01825.

(22) Arnett, C. H.; Kaiser, J. T.; Agapie, T. Remote Ligand Modifications Tune Electronic Distribution and Reactivity in Site-Differentiated, High-Spin Iron Clusters: Flipping Scaling Relationships. Inorg. Chem. 2019, 58 (23), 15971-15982. https://doi.org/10.1021/acs.inorgchem.9b02470.

(23) Joseph, C.; Kuppuswamy, S.; Lynch, V. M.; Rose, M. J. Fe5Mo Cluster with Iron-Carbide and Molybdenum-Carbide Bonding Motifs: Structure and Selective Alkyne Reductions. Inorg. Chem. 2018, 57 (1), 20-23. https://doi.org/10.1021/acs.inorgchem.7b02615.

(24) Churchill, M. R.; Wormald, J.; Knight, J.; Mays, M. J. Synthesis and Crystallographic Characterization of Bis(Tetramethylammonium) Carbidohexadecacarbonylhexaferrate, a Hexanuclear Carbidocarbonyl Derivative of Iron. J. Am. Chem. Soc. 1971, 93 (12), 3073-3074. https://doi.org/10.1021/ja00741a058.

(25) McGale, J.; Cutsail, G. E.; Joseph, C.; Rose, M. J.; DeBeer, S. Spectroscopic X-Ray and Mössbauer Characterization of $\mu_{6}$ and $\mu_{5}$ Iron(Molybdenum)-Carbonyl Carbide Clusters: High CarbideIron Covalency Enhances Local Iron Site Electron Density Despite Cluster Oxidation. Inorg. Chem. 2019, 58 (19), 12918-12932. https://doi.org/10.1021/acs.inorgchem.9b01870.

(26) Bradley, J. S.; Ansell, G. B.; Leonowicz, M. E.; Hill, E. W. Synthesis and Molecular Structure of $\mu_{4}$-Carbido- $\mu_{2}$-Carbonyl-Dodecacarbonyltetrairon, a Neutral Iron Butterfly Cluster Bearing an Exposed Carbon Atom. J. Am. Chem. Soc. 1981, 103 (16), 4968-4970. https://doi.org/10.1021/ja00406a062.

(27) Arnett, C. H.; Bogacz, I.; Chatterjee, R.; Yano, J.; Oyala, P. H.; Agapie, T. Mixed-Valent Diiron $\mu-$ Carbyne, $\mu$-Hydride Complexes: Implications for Nitrogenase. J. Am. Chem. Soc. 2020, 142 (44), 1879518813. https://doi.org/10.1021/jacs.0c05920.

(28) Spatzal, T.; Perez, K. A.; Howard, J. B.; Rees, D. C. Catalysis-Dependent Selenium Incorporation and Migration in the Nitrogenase Active Site Iron-Molybdenum Cofactor. eLife 2015, 4, e11620. https://doi.org/10.7554/eLife.11620.

(29) Spatzal, T.; Perez, K. A.; Einsle, O.; Howard, J. B.; Rees, D. C. Ligand Binding to the FeMoCofactor: Structures of CO-Bound and Reactivated Nitrogenase. Science 2014, 345 (6204), 1620. https://doi.org/10.1126/science.1256679.

(30) Sippel, D.; Rohde, M.; Netzer, J.; Trncik, C.; Gies, J.; Grunau, K.; Djurdjevic, I.; Decamps, L.; Andrade, S. L. A.; Einsle, O. A Bound Reaction Intermediate Sheds Light on the Mechanism of Nitrogenase. Science 2018, 359 (6383), 1484. https://doi.org/10.1126/science.aar2765.

(31) Xu, G.; Wang, Z.; Ling, R.; Zhou, J.; Chen, X.-D.; Holm, R. H. Ligand Metathesis as Rational Strategy for the Synthesis of Cubane-Type Heteroleptic Iron-Sulfur Clusters Relevant to the FeMo Cofactor. Proc Natl Acad Sci USA 2018, 115 (20), 5089. https://doi.org/10.1073/pnas.1801025115.

(32) Fomitchev, D. V.; McLauchlan, C. C.; Holm, R. H. Heterometal Cubane-Type $\mathrm{MFe}_{3} \mathrm{~S}_{4}$ Clusters (M $=$ Mo, V) Trigonally Symmetrized with Hydrotris(Pyrazolyl)Borate(1-) and

Tris(Pyrazolyl)Methanesulfonate(1-) Capping Ligands. Inorg. Chem. 2002, 41 (4), 958-966.

https://doi.org/10.1021/ic011106d. 
(33) Hong, D.; Zhang, Y.; Holm, R. H. Heterometal Cubane-Type WFe $\mathrm{S}_{4}$ and Related Clusters Trigonally Symmetrized with Hydrotris(3,5-Dimethylpyrazolyl)Borate. Inorganica Chimica Acta 2005, 358 (7), 2303-2311. https://doi.org/10.1016/j.ica.2004.11.051.

(34) Lavallo, V.; Ishida, Y.; Donnadieu, B.; Bertrand, G. Isolation of Cyclopropenylidene-Lithium Adducts: The Weiss-Yoshida Reagent. Angew. Chem. Int. Ed. 2006, 45 (40), 6652-6655. https://doi.org/10.1002/anie.200602701.

(35) Martinez, J. L.; Lin, H.-J.; Lee, W.-T.; Pink, M.; Chen, C.-H.; Gao, X.; Dickie, D. A.; Smith, J. M. Cyanide Ligand Assembly by Carbon Atom Transfer to an Iron Nitride. J. Am. Chem. Soc. 2017, 139 (40), 14037-14040. https://doi.org/10.1021/jacs.7b08704.

(36) Deng, L.; Holm, R. H. Stabilization of Fully Reduced Iron-Sulfur Clusters by Carbene Ligation: The $\left[\mathrm{Fe}_{n} \mathrm{~S}_{n}\right]^{0}$ Oxidation Levels $(\mathrm{n}=4, \mathrm{8})$. J. Am. Chem. Soc. 2008, 130 (30), 9878-9886. https://doi.org/10.1021/ja802111w.

(37) Evans, M. E.; Li, T.; Jones, W. D. C-H vs C-C Bond Activation of Acetonitrile and Benzonitrile via Oxidative Addition: Rhodium vs Nickel and $\mathrm{Cp}^{*}$ vs $\mathrm{Tp}^{\prime}\left(\mathrm{Tp}^{\prime}=\right.$ Hydrotris(3,5-Dimethylpyrazol-1-yl)Borate, $C p^{*}=$ H5-Pentamethylcyclopentadienyl). J. Am. Chem. Soc. 2010, 132 (45), 16278-16284. https://doi.org/10.1021/ja107927b.

(38) Kent, G. T.; Staun, S. L.; Wu, G.; Hayton, T. W. Reactivity of $\left[\mathrm{Ce}\left(\mathrm{NR}_{2}\right)_{3}\right]\left(\mathrm{R}=\mathrm{SiMe}_{3}\right)$ with Prospective Carbon Atom Transfer Reagents. Organometallics 2020. https://doi.org/10.1021/acs.organomet.0c00186.

(39) Chu, C. T.-Wah.; Dahl, L. F. Structural Characterization of $\left[\mathrm{AsPh}_{4}\right]^{+}\left[\mathrm{Fe}_{4}(\mathrm{NO})_{7}\left(\mu_{3}-\mathrm{S}\right)_{3}\right]^{-}$. Stereochemical and Bonding Relationship of the Roussin Black Monoanion with the Red Ethyl Ester, $\mathrm{Fe}_{2}(\mathrm{NO})_{4}\left(\mu_{2}-\mathrm{SC}_{2} \mathrm{H}_{5}\right)_{2}$, and $\mathrm{Fe}_{4}(\mathrm{NO})_{4}\left(\mu_{3}-\mathrm{S}\right)_{4}$. Inorg. Chem. 1977, $16(12), 3245-3251$. https://doi.org/10.1021/ic50178a052.

(40) Fritsch, J.; Scheerer, P.; Frielingsdorf, S.; Kroschinsky, S.; Friedrich, B.; Lenz, O.; Spahn, C. M. T. The Crystal Structure of an Oxygen-Tolerant Hydrogenase Uncovers a Novel Iron-Sulphur Centre. Nature 2011, 479 (7372), 249-252. https://doi.org/10.1038/nature10505.

(41) Coucouvanis, D.; Han, J.; Moon, N. Synthesis and Characterization of Sulfur-Voided Cubanes. Structural Analogues for the $\mathrm{MoFe}_{3} \mathrm{~S}_{3}$ Subunit in the Nitrogenase Cofactor. J. Am. Chem. Soc. 2002, 124 (2), 216-224. https://doi.org/10.1021/ja0110832.

(42) Powers, T. M.; Fout, A. R.; Zheng, S.-L.; Betley, T. A. Oxidative Group Transfer to a Triiron Complex to Form a Nucleophilic $\mu_{3}-\mathrm{Nitride},\left[\mathrm{Fe}_{3}\left(\mu_{3}-\mathrm{N}\right)\right]^{-}$. J. Am. Chem. Soc. 2011, 133 (10), 3336-3338. https://doi.org/10.1021/ja2003445.

(43) Horitani, M.; Shisler, K.; Broderick, W. E.; Hutcheson, R. U.; Duschene, K. S.; Marts, A. R.; Hoffman, B. M.; Broderick, J. B. Radical SAM Catalysis via an Organometallic Intermediate with an Fe[5'-C]-Deoxyadenosyl Bond. Science 2016, 352 (6287), 822. https://doi.org/10.1126/science.aaf5327.

(44) Ye, M.; Thompson, N. B.; Brown, A. C.; Suess, D. L. M. A Synthetic Model of Enzymatic $\left[\mathrm{Fe}_{4} \mathrm{~S}_{4}\right]-$ Alkyl Intermediates. J. Am. Chem. Soc. 2019. https://doi.org/10.1021/jacs.9b06975.

(45) Sherbow, T. J.; Zakharov, L. N.; Johnson, D. W.; Pluth, M. D. Hydrosulfide Oxidation at a Molybdenum Tetrasulfido Complex. Inorg. Chem. 2020, 59 (21), 15574-15578.

https://doi.org/10.1021/acs.inorgchem.0c02622.

(46) Kowalska, J. K.; Henthorn, J. T.; Van Stappen, C.; Trncik, C.; Einsle, O.; Keavney, D.; DeBeer, S. X-Ray Magnetic Circular Dichroism Spectroscopy Applied to Nitrogenase and Related Models: 
Experimental Evidence for a Spin-Coupled Molybdenum(III) Center. Angew. Chem. Int. Ed. 2019, 58 (28), 9373-9377. https://doi.org/10.1002/anie.201901899.

(47) Majumdar, A.; Holm, R. H. Specific Incorporation of Chalcogenide Bridge Atoms in Molybdenum/Tungsten-Iron-Sulfur Single Cubane Clusters. Inorg. Chem. 2011, 50 (21), 11242-11251. https://doi.org/10.1021/ic2018117.

(48) Venkateswara Rao, P.; Holm, R. H. Synthetic Analogues of the Active Sites of Iron-Sulfur Proteins. Chem. Rev. 2004, 104 (2), 527-560. https://doi.org/10.1021/cr020615+.

(49) Spatzal, T.; Aksoyoglu, M.; Zhang, L.; Andrade, S. L. A.; Schleicher, E.; Weber, S.; Rees, D. C.; Einsle, O. Evidence for Interstitial Carbon in Nitrogenase FeMo Cofactor. Science 2011, 334 (6058), 940. https://doi.org/10.1126/science.1214025.

(50) Tano, H.; Tajima, R.; Miyake, H.; Itoh, S.; Sugimoto, H. Selenidobis(Dithiolene)Metal(IV) Complexes (Metal $\mathrm{M}=\mathrm{Mo}, \mathrm{W}$ ) Potentially Related to the Nicotinic Acid Hydroxylase Reaction Center: Redox Aspects in Electrochemistry and Oxygen Atom Transfer from $\mathrm{Me}_{3} \mathrm{NO}$ to $\mathrm{M}^{\mathrm{IV}}$ Centers. Inorg. Chem. 2008, 47 (17), 7465-7467. https://doi.org/10.1021/ic8009942.

(51) Čorić, I.; Holland, P. L. Insight into the Iron-Molybdenum Cofactor of Nitrogenase from Synthetic Iron Complexes with Sulfur, Carbon, and Hydride Ligands. J. Am. Chem. Soc. 2016, 138 (23), 72007211. https://doi.org/10.1021/jacs.6b00747.

(52) Henthorn, J. T.; Arias, R. J.; Koroidov, S.; Kroll, T.; Sokaras, D.; Bergmann, U.; Rees, D. C.; DeBeer, S. Localized Electronic Structure of Nitrogenase FeMoco Revealed by Selenium K-Edge High Resolution X-Ray Absorption Spectroscopy. J. Am. Chem. Soc. 2019, 141 (34), 13676-13688. https://doi.org/10.1021/jacs.9b06988.

(53) Speelman, A. L.; Čorić, I.; Van Stappen, C.; DeBeer, S.; Mercado, B. Q.; Holland, P. L. Nitrogenase-Relevant Reactivity of a Synthetic Iron-Sulfur-Carbon Site. J. Am. Chem. Soc. 2019, 141 (33), 13148-13157. https://doi.org/10.1021/jacs.9b05353. 
Figures
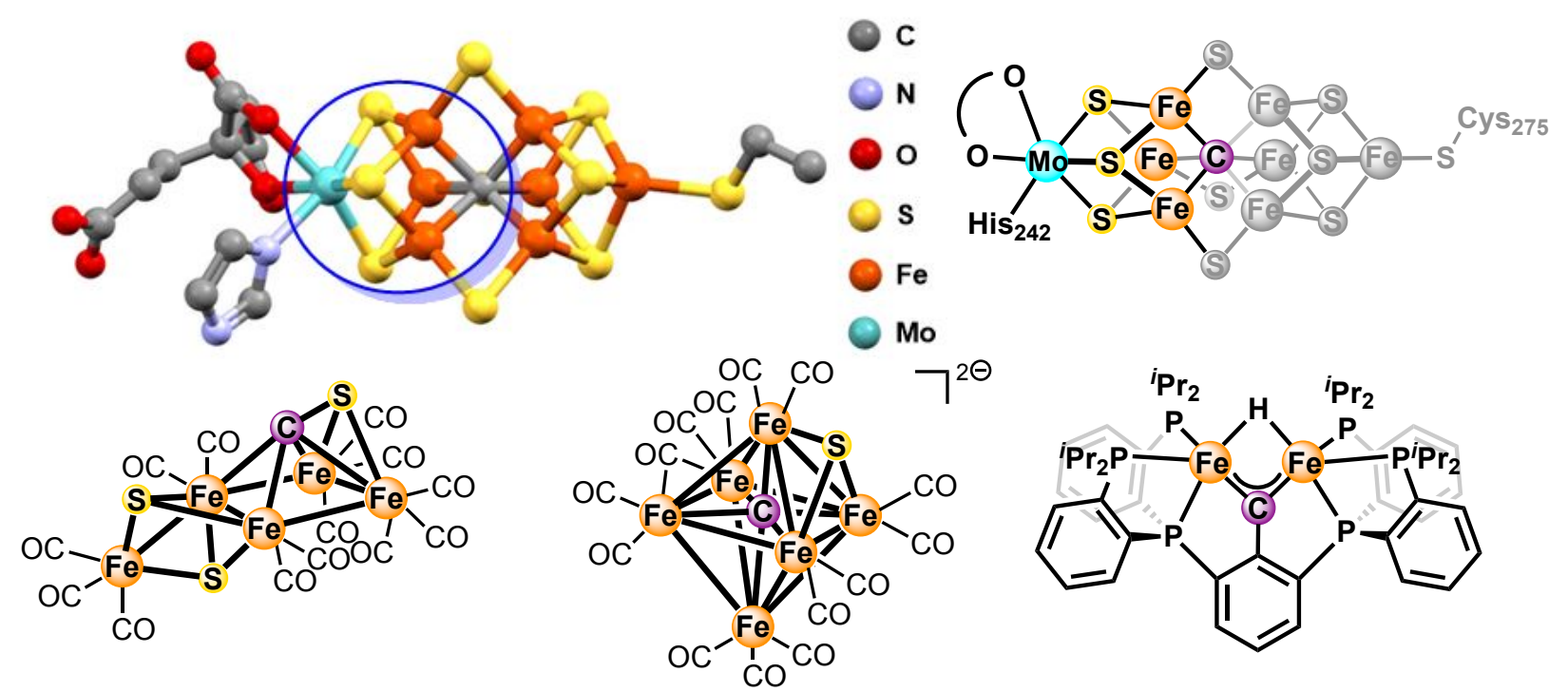

Figure 1: Top: Structure of FeMoco in Mo-dependent nitrogenase from PDB structure 3U7Q with blue circle emphasizing the cubane subsite and its schematic representation highlighting in color the subsite of focus in this study; bottom: carbyne and carbide containing model complexes. ${ }^{9-11}$ 


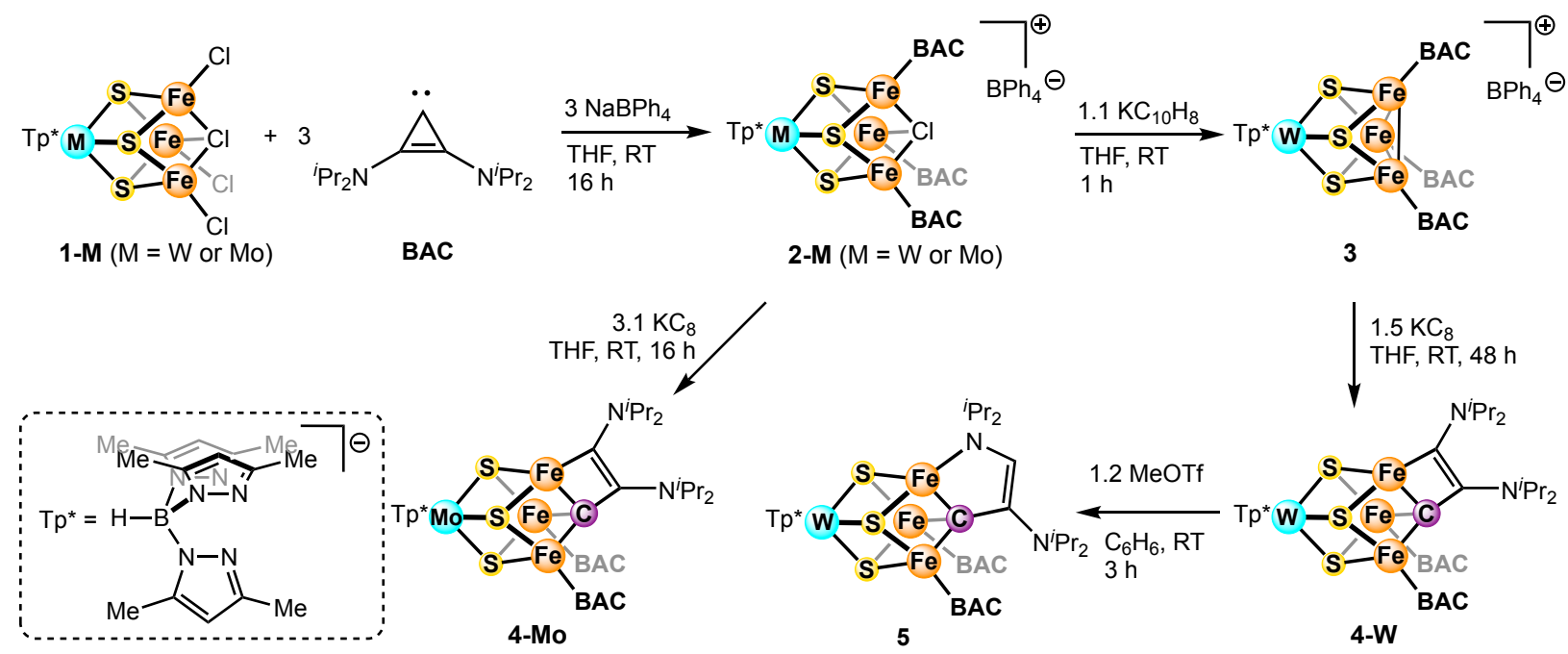

Figure 2: Synthesis of carbyne-containing clusters. 

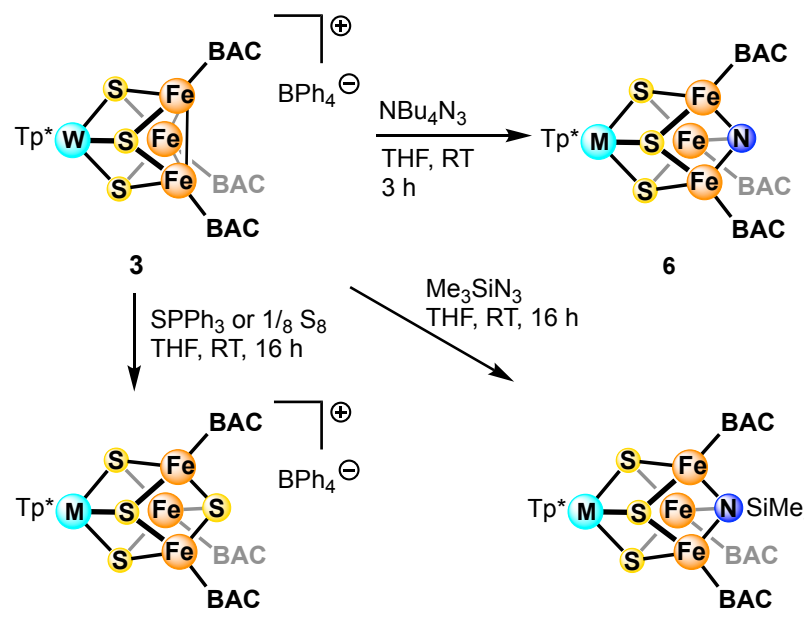

6

8

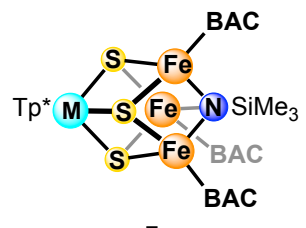

Figure 3: Synthesis of nitride, imide, and sulfide-containing clusters. 


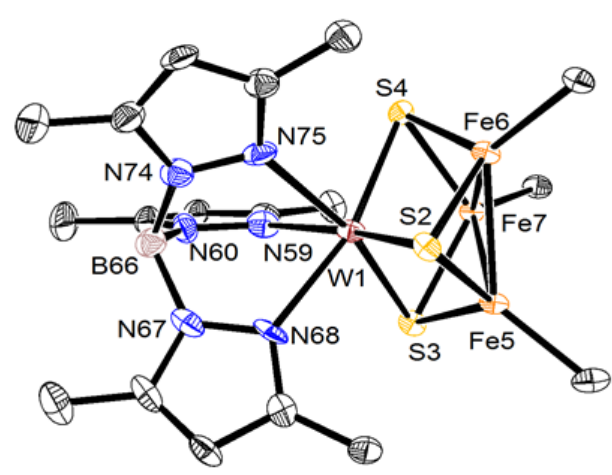

3

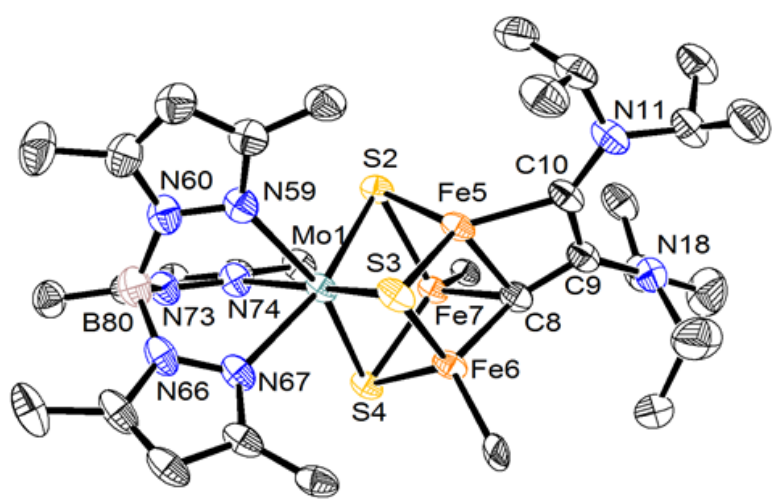

4-Mo

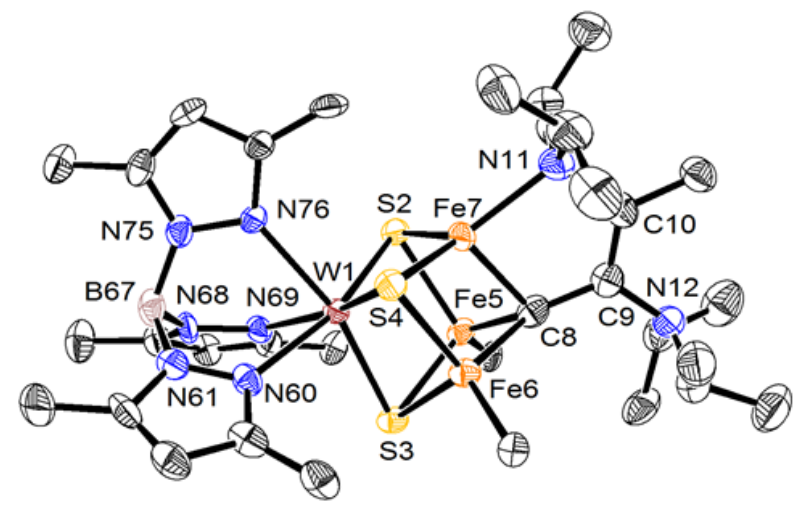

5

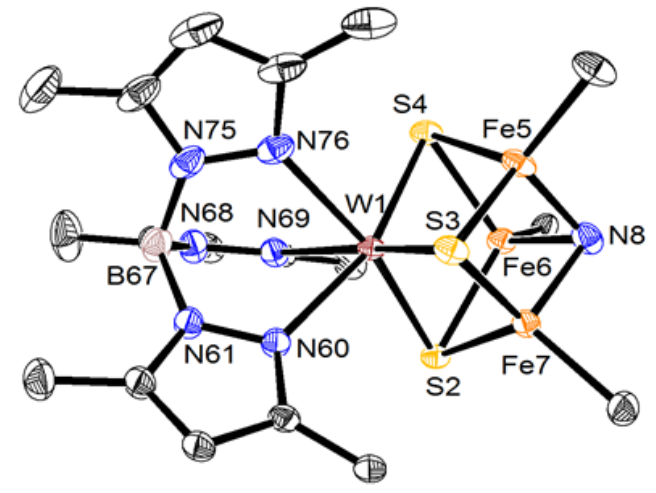

6

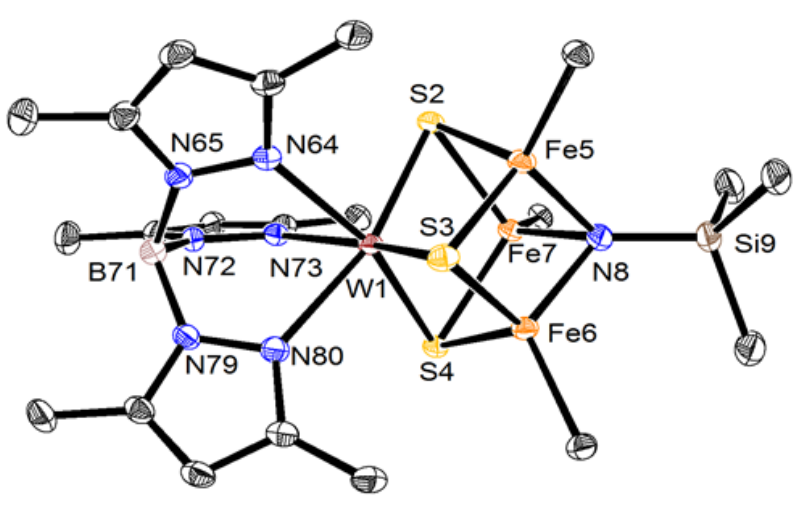

7

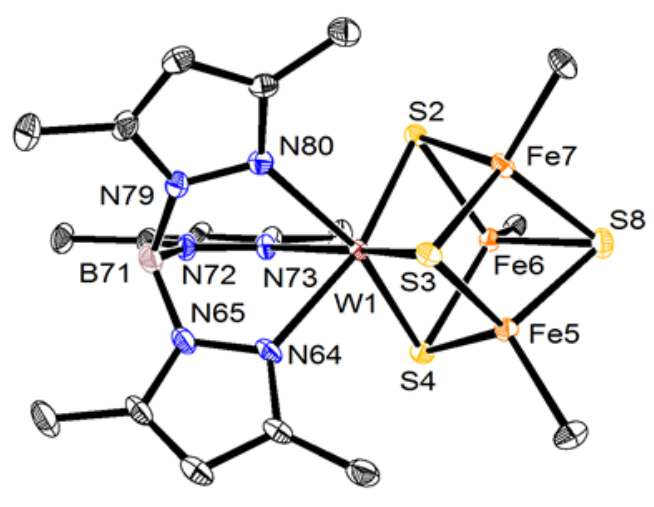

8

Figure 4: Crystal structures of 3, 4-Mo, 5, 6, 7, and 8 (see Supporting Information for the isostructural cluster 4-W). Hydrogen atoms, counteranions, and the BAC ligand except for the carbene $C$ are omitted for clarity. Ellipsoids are shown at $50 \%$ probability. 


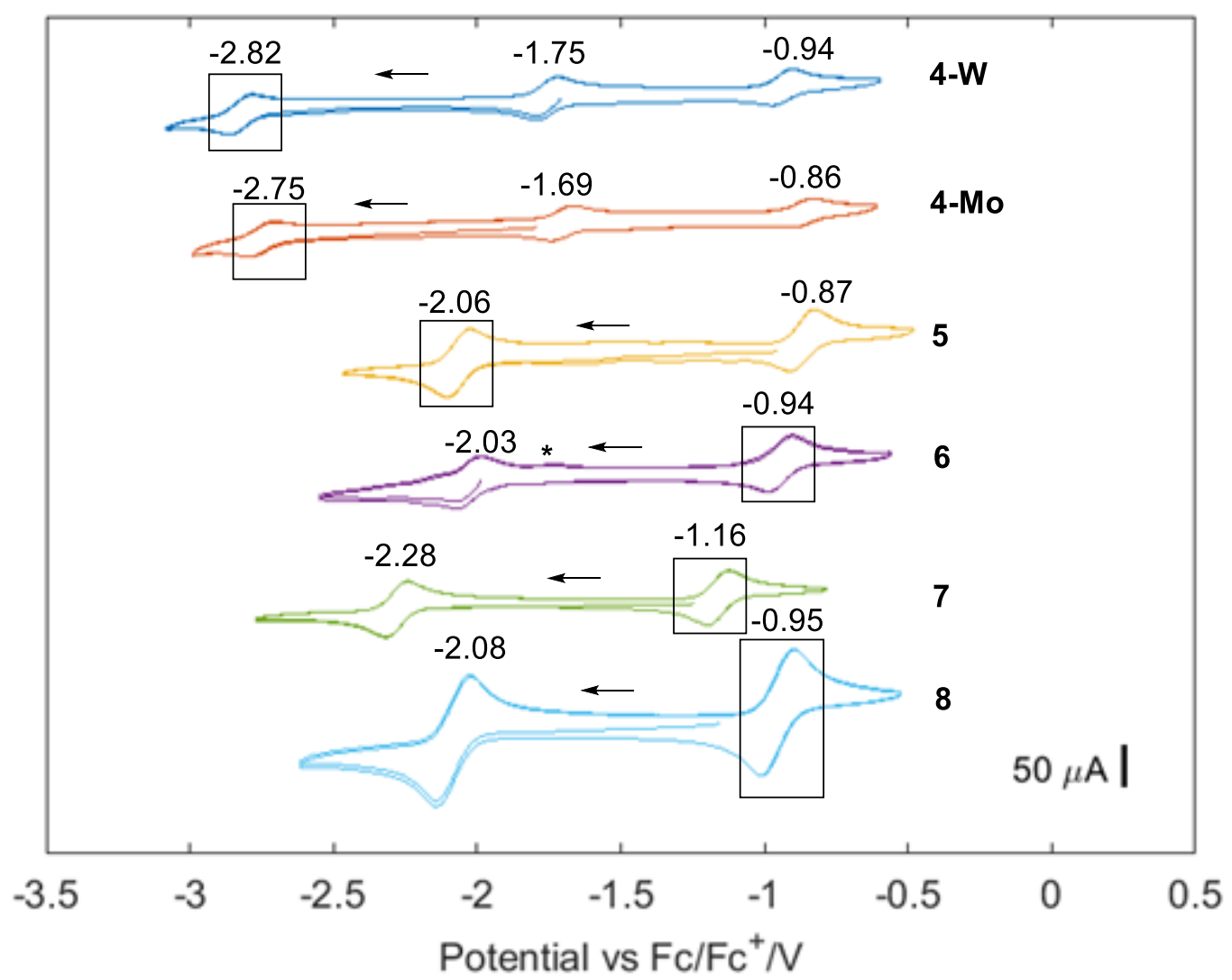

Figure 5: Cyclic voltammetry scans for compounds 4 - 8. The boxed peaks correspond to the $\left(\mathrm{MFe}_{3}\right)^{11+} /\left(\mathrm{MFe}_{3}\right)^{10+}$ couple of interest. The potential is indicated above each wave. Conditions: $\sim 2.5 \mathrm{mM}$ cluster in in MeCN with 0.2 $\mathrm{M} \mathrm{TBAPF}_{6}$, scan rates of $200 \mathrm{mV} \mathrm{s}^{-1}$ (4-W, 5 to 8 ) or $250 \mathrm{mV} \mathrm{s}^{-1}$ (4-Mo). Asterisk $\left(^{*}\right)$ indicates small amounts of $\mathbf{4 - W}$ impurity in samples of 6 . 
